\title{
CRESCIMENTO INICIAL DE KIWANO EM DIFERENTES TIPOS DE SUBSTRATOS
}

\author{
SCHMILDT, Omar $^{1}$ \\ OLIVEIRA, Marcio José Vieira de ${ }^{2}$ \\ SCHMILDT, Edilson Romais ${ }^{3}$ \\ ALEXANDRE, Rodrigo Sobreira ${ }^{3}$ \\ CZEPAK, Marcio Paulo ${ }^{3}$
}

RESUMO: O kiwano (Cucumis metuliferus) é uma espécie exótica, pertencente à família das Cucurbitáceas, possuindo um grande potencial para comercialização. Este trabalho teve como objetivo conhecer mais sobre a cultura do kiwano, através do seu crescimento inicial em diferentes tipos de substratos, visto que são poucos os trabalhos relacionados com esta cultura. $\mathrm{O}$ trabalho foi realizado em casa de vegetação, em Alegre-ES, num delineamento inteiramente casualizado com quatro repetições. Os tratamentos utilizados foram constituídos dos seguintes substratos: Plantmax ${ }^{\circledR}$; composto de leguminosa Acacia sp; composto de casca de arroz carbonizada + húmus; composto de palha de milho + esterco; e composto de vermiculita + húmus. Aos 28 dias após a semeadura foram avaliadas a altura, a massa de matéria fresca e a massa de matéria seca das plântulas. O substrato Plantmax ${ }^{\circledR}$ se mostrou mais eficiente na propagação inicial do kiwano, apresentando médias estatisticamente superiores para as variáveis analisadas, sendo, portanto indicado para a produção de mudas desta cultura.

Palavras-chave: Cucumis metuliferus. Propagação. Produção vegetal.

\section{KIWANO INITIAL GROWTH IN DIFFERENT TYPES OF SUBSTRATES}

SUMMARY: The kiwano (Cucumis metuliferus) is an exotic species, belonging to the Cucurbitaceae family, possessing a great potential for commercialization. This study aimed to learn more about the culture of kiwano through its initial growth on different substrates, since there are few works related to this culture. The study was carried out in a greenhouse in Alegre-ES, a completely randomized design with four replications. The treatments consisted of the following substrates: Plantmax ${ }^{\circledR}$, composed of legume Acacia sp; composed of rice husk carbornized + humus, composed of corn stover + manure and compost humus + vermiculite. At 28 days after sowing were evaluated height, fresh weight and dry weight of seedlings. The substrate Plantmax ${ }^{\circledR}$ was more effective in the initial spread of the kiwano, with statistically higher in those variables and is therefore suitable for the production of seedlings of this crop.

Keywords: Cucumis metuliferus. Propagation. Crop production.

\section{INTRODUÇÃO}

O pepino africano (Cucumis metuliferus) é um fruto oriundo da África, da localidade do deserto de Calaari, no Brasil ele é conhecido como kiwano, kino ou ainda chifrudo. É cultivado principalmente no sul e no centro do continente africano e também nos Estados Unidos, em Israel, no Quênia, na Nova Zelândia mais recentemente, também na Itália, em Portugal e na Alemanha. Além de ser uma planta ornamental,

\footnotetext{
${ }^{1}$ Pós-Doutorando CAPES. Centro Universitário Norte do Espírito Santo/Universidade Federal do Espírito Santo. Email: omar-schmildt@ig.com.br.

${ }^{2}$ Doutorando em Produção Vegetal . Centro de Ciências Agrárias/Universidade Federal do Espírito Santo.

${ }^{3}$ Professor Doutor. Centro Universitário Norte do Espírito Santo/ Universidade Federal do Espírito Santo.
} 
seu fruto, rico em potássio, e pobre em sódio, é recomendado como diurético e para pessoas diabéticas. É usado in natura no preparo de refrescos, drinques, saladas, além de ingrediente em geléia, cozidos de carne e peixe. Suas sementes são vermífugas e suas folhas podem ser consumidas após cozimento (FUNDACIÓN EROSKI, 2005).

A propagação do kiwano é feita via seminífera, sendo a temperatura entre $20^{\circ}$ e $35^{\circ} \mathrm{C}$ considerada ótima para a germinação e o cultivo (BENZIONI, 1997), podendo assim ser cultivado no Brasil. Esta espécie é pouco conhecida e estudada, necessitando-se assim de mais estudos sobre os aspectos propagativos. O conhecimento das condições ideais para a germinação, principalmente relacionados ao tipo de substrato, é de suma importância.

Dentre as características desejáveis dos substratos, destacam-se: baixo custo, adequada capacidade de troca catiônica, disponibilidade próximo à região de consumo, boa aeração, além de propiciar uma apropriada retenção de umidade e favorecer a atividade fisiológica das raízes (HOFFMANN; NACHTIGAL; FACHINELLO apud FACHINELLO; HOFFMANN; NACHTIGAL, 2005; OLIVEIRA; HERNANDEZ; ASSIS JÚNIOR, 2009; HARTMANN et al., 2011).

O substrato básico para a produção de mudas é do tipo orgânico como os compostos de esterco de curral curtido, pó da casca de coco seco, cascas de eucalipto e pinus, bagacilho de cana, húmus de minhoca, entre outros. Esses substratos são, geralmente, utilizados em misturas com outros substratos de menor densidade como a casca de arroz carbonizada e a vermiculita. A adição desses substratos reduz a densidade média da mistura, melhorando suas condições de aeração e drenagem (GONÇALVES; BENEDETTI, 2000). Normalmente para a obtenção de mudas de pepino, que é da mesma família do kiwano, utiliza-se diferentes tipos de substratos como compostos de materiais orgânicos leves, corrigidos e enriquecidos de nutrientes solúveis (MINAMI, 1995).

O substrato comercial Plantmax ${ }^{\circledR}$ têm se mostrado com boas propriedades físicas e químicas para o cultivo de plântulas de figos provenientes da cultura de tecidos (FRÁGUAS; PEREIRA; PASQUAL, 2002), ou para o cultivo via seminífera com moringa (BEZERRA; MOMENTE; MEDEIROS FILHO, 2004), alface (TRANI et al. 2007) e melão cv. AF682 (ARAGÃO et al., 2011).

Este trabalho objetivou estudar o crescimento inicial das plântulas de kiwano no cultivo em bandejas com diferentes tipos de substratos.

\section{MATERIAL E MÉTODOS}

O trabalho foi realizado em casa de vegetação do Instituto Federal do Espírito Santo, Campus de Alegre/ES.

As sementes, provenientes de fruto comercial, foram lavadas e secas em temperatura ambiente, sendo semeadas logo em seguida em bandeja de isopor de 200 células e cultivadas em bancadas a uma altura de $1,0 \mathrm{~m}$. A irrigação foi feita por aspersores uma vez ao dia.

$\mathrm{O}$ experimento foi disposto em delineamento inteiramente casualizado onde se testou cinco tratamentos com quatro repetições por bandeja, sendo cada parcela experimental constituída de 20 plântulas. Os tratamentos foram constituídos dos seguintes substratos: 1 - Plantmax ${ }^{\circledR} ; 2$ - composto de leguminosa Acacia sp; 3 - composto de casca de arroz carbonizada + húmus; 4 - composto de palha de milho + esterco e 5 - composto de vermiculita + húmus.

O composto de leguminosas Acacia sp foi curtido por três meses, sendo utilizado sem mistura para a composição do substrato. No composto palha de milho + esterco, foi utilizado 50\% de restos da palha de milho junto aos 50\% de esterco, ambos curtidos. Para a composição do substrato casca de arroz carbonizada + húmus, foi utilizado 50\% de carvão da casca de arroz, mais 50\% de húmus de minhoca, já 
para o composto vermiculita + húmus, preparou-se uma mistura de 50\% de húmus de minhoca com 50\% de vermiculita. Todos os materiais utilizados para a composição dos substratos foram obtidos no Instituto Federal do Espírito Santo de Alegre.

Os tratamentos não receberam nenhum tipo de adubação durante a fase de crescimento das mudas.

Foram avaliadas a altura, a massa de matéria fresca e a massa de matéria seca das plântulas aos 28 dias após a semeadura. A altura da plântula foi determinada, medindo-se a base do colo até a gema apical, com o auxílio de régua milimetrada. A massa de matéria fresca foi mensurada por meio da pesagem individual de cada plântula, em balança analítica. Para medir a massa de matéria seca, utilizou-se a estufa à $70^{\circ} \mathrm{C}$ por 72 horas para secagem do material vegetal, com posterior pesagem em balança analítica.

Os dados foram submetidos à análise de variância, e posteriormente as médias foram comparadas pelo teste Tukey a $5 \%$ de probabilidade.

\section{RESULTADOS E DISCUSSÃO}

De acordo com a análise de variância (Tabela 1), houve diferença significativa em todas as

TABELA 1 - Resumo da análise de variância da altura, massa de matéria fresca e massa de matéria seca de kiwano (Cucumis metuliferus) aos 28 dias após semeadura em cinco tipos de substrato

\begin{tabular}{ccccc}
\hline & & \multicolumn{3}{c}{ Quadrado médio } \\
\cline { 3 - 5 } $\begin{array}{c}\text { Fonte de } \\
\text { variação }\end{array}$ & $\begin{array}{c}\text { Graus de } \\
\text { liberdade }\end{array}$ & Altura $(\mathrm{cm})$ & $\begin{array}{c}\text { Massa de matéria } \\
\text { fresca }(\mathrm{g})\end{array}$ & $\begin{array}{c}\text { Massa de matéria } \\
\text { seca }(\mathrm{g})\end{array}$ \\
\hline Substratos & 4 & $0,3247^{*}$ & $1,5623^{*}$ & $0,0572^{*}$ \\
Resíduo & 15 & 0,0475 & 0,2986 & 0,0105 \\
\hline Média & & 3,75 & 6,98 & 1,38 \\
$\mathrm{CV}_{(\%)}$ & & 5,81 & 7,93 & 7,43 \\
\hline
\end{tabular}

* Significativo a 5\% pelo teste de $\mathrm{F}$.

variáveis analisadas para os substratos utilizados na produção de mudas de kiwano.

Ao comparar os substratos (Tabela 2), pode-se observar que o Plantmax ${ }^{\circledR}$ foi superior estatisticamente aos demais em relação às médias analisadas para as características altura, massa de matéria fresca e massa de matéria seca. No entanto, a porcentagem de emergência foi de $100 \%$ para todos os tratamentos, indicando que o tipo de substrato não influenciou na germinação de sementes de kiwano, havendo em todos eles uma condição ótima de temperatura para a germinação, conforme Benzioni (1997). Contudo, houve crescimento inicial diferenciado das mudas, daí justifica-se a importância da utilização de diferentes substratos na produção de mudas. No caso deste experimento foi utilizada a mistura de diferentes tipos de materiais para composição dos substratos a fim de reduz a densidade média da mistura, para melhorar as suas condições de aeração e drenagem (GONÇALVES; BENEDETTI, 2000) e favorecer a atividade fisiológica das raízes (HOFFMANN; NACHTIGAL; FACHINELLO apud FACHINELLO; HOFFMANN; NACHTIGAL, 2005; OLIVEIRA; HERNANDEZ; ASSIS JÚNIOR, 2009; HARTMANN et al., 2011). 
TABELA 2- Valores médios para porcentagem de emergência, altura, massa de matéria fresca e seca de kiwano (Cucumis metuliferus) aos 28 dias após semeadura em cinco tipos de substratos

\begin{tabular}{lcccc}
\hline Substratos & \multicolumn{3}{c}{ Médias $^{1 /}$} \\
\cline { 2 - 5 } & $\begin{array}{c}\text { Emergência } \\
(\%)\end{array}$ & $\begin{array}{c}\text { Altura } \\
(\mathrm{cm})\end{array}$ & $\begin{array}{c}\text { Massa de matéria } \\
\text { fresca(g) }\end{array}$ & $\begin{array}{c}\text { Massa de matéria } \\
\text { seca(g) }\end{array}$ \\
\hline Plantmax $^{\circledR}$ & 100,00 & $5,94 \mathrm{a}$ & $13,89 \mathrm{a}$ & $2,30 \mathrm{a}$ \\
Leguminosa Acacia sp & 100,00 & $3,50 \mathrm{~b}$ & $6,35 \mathrm{~b}$ & $1,33 \mathrm{~b}$ \\
Casca de arroz & 100,00 & $3,27 \mathrm{~b}$ & $5,60 \mathrm{bc}$ & $1,25 \mathrm{bc}$ \\
carbonizada + húmus & 100,00 & $3,26 \mathrm{~b}$ & $4,54 \mathrm{c}$ & $1,05 \mathrm{~cd}$ \\
Palha de milho + esterco & 100,00 & $2,78 \mathrm{c}$ & $4,52 \mathrm{c}$ & $0,97 \mathrm{~d}$ \\
Vermiculita + húmus & & 0,47 & 1,19 & 0,22 \\
\hline D.M.S. & &
\end{tabular}

${ }^{1 /}$ Médias seguidas de mesma letra na coluna não diferem entre si pelo teste de Tukey a 5\% de probabilidade.

O composto vermiculita + húmus apresentou a menor média de altura $(2,78 \mathrm{~cm})$ dentre todos os tratamentos. Já com relação à massa de matéria fresca, o composto vermiculita + húmus não diferiu estatisticamente dos compostos palha de milho + esterco e casca de arroz carborizado + húmus, e quanto à massa de matéria seca, o mesmo não diferiu estatisticamente em relação ao composto palha de milho + esterco, mas diferiu dos demais compostos (Tabela 2). Os resultados encontrados neste experimento com a utilização do composto vermiculita + húmus, pode ser explicado conforme Gonçalves; Poggiani (1996), onde citam que ambos compostos possuem alta porosidade, porém o húmus possui apenas microporosidade elevada, enquanto a vermiculita apresenta equilíbrio entre macro e microporosidade. Esta característica do húmus pode ter levado o substrato a ter uma redução na aeração, acarretando prejuízos no desenvolvimento radicular, e por conseqüência diminuição no crescimento das plântulas.

O substrato Plantmax ${ }^{\circledR}$ proporcionou maior crescimento em altura $(5,94 \mathrm{~cm})$, massa de matéria fresca $(13,89 \mathrm{~g})$ e seca das plântulas $(2,30 \mathrm{~g})$, diferindo estatisticamente dos demais substratos. Quanto à altura, massa de matéria fresca e seca da parte aérea das plântulas, os resultados (Tabela 2) concordam com os encontrados por Aragão et al. (2011), quando trabalharam com melão cv. AF682, onde o substrato Plantmax $^{\circledR}$ foi superior aos demais compostos. Fráguas, Pereira e Pasqual (2002) também obtiveram melhores resultados de altura, massa de matéria fresca e seca da parte aérea ao aclimatar plântulas de figos provenientes de cultivo in vitro, utilizando o substrato Plantmax ${ }^{\circledR}$.

Outros autores também verificaram o bom desempenho do substrato Plantmax ${ }^{\circledR}$ ao trabalhar com outras espécies que não são da mesma família do kiwano, como moringa (BEZERRA; MOMENTE; MEDEIROS FILHO, 2004) e alface (TRANI et al., 2007), obtendo-se melhor crescimento da parte aérea.

A utilização de composto de leguminosa Acacia sp, quando comparado com os demais compostos (Tabela 2), pode ser considerado uma segunda alternativa para a produção de mudas de kiwano, por se tratar de um material de fácil acesso e economicamente viável.

\section{CONCLUSÃO}

O tipo de substrato não influência na emergência das plântulas de kiwano.

O substrato comercial Plantmax ${ }^{\circledR}$ é o mais eficiente para o processo de produção de mudas de kiwano em bandejas de isopor de 200 células. 
O composto de Acacia sp é uma segunda alternativa para o preparo de mudas de kiwano a fim de diminuir custos.

\section{REFERÊNCIAS}

ARAGÃO, C.A. et al. Qualidade de mudas de melão produzidas em diferentes substratos. Revista Caatinga, v.24, n.3, p.209-214, 2011.

BENZIONI, A. Kiwano. Disponível em: 〈www.hort.purdue.edu/newcrop/cropfactsheets/kiwano.html〉. Acesso em: 27 ago. 2011.

BEZERRA, A.M.E.; MOMENTÉ, V.G.; MEDEIROS FILHO, S. Germinação de sementes e desenvolvimento de plântulas de moringa (Moringa oleiferaLam.) em função do peso da semente e do tipo de substrato. Horticultura Brasileira, v.22, n.2, p.295-299, 2004.

FRÁGUAS, C.B.; PEREIRA, A.R.; PASQUAL, M. Aclimatacão de plântulas de Ficuscarica cv. Roxo-deValinhos micropropagadas. In: CONGRESSO BRASILEIRO DE FRUTICULTURA, 17., 2002, Belém. Resumos..., Pará: SBF, 2002. CD-ROM

FUNDACIÓN EROSKI. Kiwano. Disponível em: <www.frutas.consumer.es/documentos/tropicales/kiwano/receta.php>. Acesso em: 20 jul. 2011.

GONÇALVES, J.L.M.; BENEDETTI, V. Nutrição e fertilização florestal. Piracicaba: IPEF. 2000. 427p. GONÇALVES, J.L.M.; POGGIANI, F. Substratos para produção de mudas florestais. In: CONGRESSO LATINO-AMERICANO DE CIÊNCIA DO SOLO, 13.,1996, Águas de Lindóia. Resumos...,Piracicaba: Sociedade Latino-Americana de Ciência do Solo,1996. CD-ROM

HARTMANN, H.T.et al. Hartman ;Kester's Plant propagation: principles and practices. 8. ed. New Jersey: Prentice Hall. 2011. 928p.

HOFFMANN, A.; NACHTIGAL, J.C.; FACHINELLO, J.C. Infra-estrutura para propagação de plantas frutíferas. In: FACHINELLO, J.C.; HOFFMANN, A.; NACHTIGAL, J.C. Propagação de plantas frutíferas. Brasília: Embrapa Informação Tecnológica, 2005. p.1-44.

MINAMI, K. Produção de mudas de alta qualidade em horticultura. Campinas: Fundação Farah Maluf. 1995. 128p.

OLIVEIRA, A.B.; HERNANDEZ, F.F.F.; ASSIS JÚNIOR, R.N. Absorção de nutrientes em mudas de berinjela cultivadas em pó de coco verde. Revista Caatinga, v.22, n.2, p.139-143, 2009.

TRANI, P.E.et al. Avaliação de substratos para a produção de mudas de alface. Horticultura Brasileira, v.25, n.2, p.256-260, 2007. 
